\title{
Coconut Peeling and Splitting Machine Design Using the TRIZ Method
}

\author{
Perancangan Mesin Pengupas dan Pembelah Kelapa dengan Menggunakan Metode \\ TRIZ \\ Yohanes Patrik Adventus Banda ${ }^{1}$, Julius Mulyono ${ }^{2^{*}}$, Hadi Santosa ${ }^{3}$ \\ 1,2,3 Jurusan Teknik Industri, Fakultas Teknik, \\ Universitas Katolik Widya Mandala Surabaya \\ Email* : juliusnyamulyono@ukwms.ac.id
}

\begin{abstract}
Copra is one of the most interesting materials, is a type of coconut which is dried using a heating process. Copra is commonly used as a part of material to produce cleanser, for the human body, such as soap and shampoo. There is a big opportunity for using copra, so we need to design an equipment for supporting copra production efficiently and faster. This research aim is to help the farmers, so they can meet market needs which are increasing day by day. Copra processing still uses traditional production methods. This study aims to design a coconut stripping and splitting device using the TRIZ method. Doing a simple experiment, resulting shorter processing of coconut peeling and breaking, showed an average time of 39.65 seconds for each piece of coconut.
\end{abstract}

Keywords: copra, stripping, splitting, TRIZ, faster.

\begin{abstract}
ABSTRAK
Kopra adalah bahan baku yang sering dicari, yaitu sejenis kelapa tua yang dikeringkan dengan proses pemanasan. Kopra biasa digunakan sebagai bahan baku untuk menghasilkan bahan pembersih bagi tubuh manusia seperti sabun dan shampo. Peluang pemanfaatan kopra sangat besar, sehingga diperlukan peralatan yang dapat mendukung produksi kopra dengan lebih efisien dan lebih cepat. Penelitian ini bermaksud agar petani kelapa dapat memenuhi kebutuhan pasar yang semakin hari semakin meningkat. Pengolahan kopra masih menggunakan metode produksi yang cukup tradisional. Jika menggunakan metode tradisional akan membutuhkan banyak waktu dan energi manusia. Penelitian ini bertujuan merancang alat pengupasan dan pembelahan kelapa menggunakan metode TRIZ. Percobaan sederhana berupa proses pengupasan dan pemecahan kelapa, menunjukkan waktu rata-rata 39,65 detik / buah.
\end{abstract}

Kata Kunci: kopra, proses, pengupasan, pembelahan, TRIZ, cepat.

\section{PENDAHULUAN}

Kelapa merupakan sebuah komoditas hasil perkebunan yang banyak diminati oleh industri saat ini dan memiliki banyak kegunaan serta manfaat. Biasanya kelapa muda dimanfaatkan untuk dijadikan minuman energi dan pengganti cairan tubuh manusia. Sedangkan kelapa tua diambil minyaknya, kemudian dijadikan bahan baku untuk memproduksi bahan kebersihan seperti sampoo, sabun, dan lain sebagainya. Kelapa tua kering yang diambil minyaknya ini sering disebut dengan kopra. Cara pembuatan kopra adalah dengan mengeringkan kelapa tua yang dipanen melalui proses pemanasan. Tidak hanya bagian daging dan airnya saja yang dapat diolah sehingga menjadi produk yang lebih ekonomis. Serabut kelapa dan juga batoknya dapat diolah kembali.

Salah satu daerah yang menghasilkan kelapa yang baik adalah Kabupaten Sikka, Provinsi Nusa Tenggara Timur. Banyak warga di Kabupaten Sikka menggantungkan hidup sebagai petani kelapa. Di Kabupaten Sikka terdapat banyak petani kelapa yang menjadikan kelapa sebagai penghasilan utama. Namun, petani kelapa di Kabupaten Sikka masih terbiasa dengan pengolahan kopra denagn cara tradisional. Hal ini menyebabkan tingginya tingkat penggunaan waktu dan tenaga. Biasanya kelapa dikeringkan untuk diambil minyaknya. Selanjutnya minyak kelapa tersebut akan dijadikan bahan baku untuk memproduksi bahan kebersihan tubuh seperti shampo, sabun mandi dan sebagainya. Sebelum dikeringkan, kelapa melalui proses pengupasan dan

Perancangan Mesin Pengupas dan Pembelah Kelapa dengan Menggunakan Metode TRIZ / Yohanes Patrik Adventus Banda, Julius Mulyono, Hadi Santosa

Peer reviewed under responsibili of Universitas Muhammadiyah Sidoarjo.

(C) 2021 Universitas Muhammadiyah Sidoarjo. All Right reserved. This is an open access article under the CC BY licence (http://creativecommons.org/licences/by/4.0/ ) 
pembelahan. Proses pembelahan dan pengupasan serabut kelapa adalah proses yang wajib dilakukan agar kelapa yang akan dikeringkan mengalami proses dengan hasil yang lebih sempurna. Di Kabupaten Sikka proses pembelahan biasanya menggunakan alat yang disebut parang (golok). Dari penelitian dan pengamatan sebelumnya, pada proses pengupasan dan pembelahan kelapa, didapatkan bahwa rata-rata waktu yang dibutuhkan untuk melakukan kedua proses tersebut adalah 2,31 menit/kelapa. Dapat dibayangkan jika hasil produksi atau panen kelapa mencapai ribuan kilogram maka akan membutuhkan waktu dan tenaga, ketika masih menggunakan cara yang konvensional atau tradisional, sehingga proses yang sederhana ini akan sangat rumit mengingat jumlah dari kelapa yang dikupas maupun dibelah berjumlah sangat banyak.

Djamalu (2016) dalam artikel berjudul Pembuatan Alat Pengupas Serabut Kelapa Sistem Putar, yang diterbitkan pada Jurnal Teknologi Pertanian Gorontalo (JTPG), menggunakan metode perancangan alat pengupas kelapa biasa dengan melakukan analisa perhitungan BEP (Break Event Point) yang bertujuan untuk menganalisa langsung besarnya biaya yang dapat dihemat melalui penggunaan alat tersebut. Alat tersebut mampu melakukan pengupasan 2 buah kelapa permenit dengan kapasitas maksimum sebesar 136 buah kelapa per jam. Alat pengupas kelapa ini masih memiliki beberapa kekurangan dalam pemanfaatannya, diantaranya kelapa yang dikupas masih memakan waktu pada proses pengolahannya sehingga kelapa tersebut dinilai kurang efisien dari segi waktu. Kekurangan dari alat tersebut dapat menimbulkan kurangnya pemanfaatan dari alat pengupas itu sendiri. Selain itu pada alat ini, kelapa belum dikupas secara menyeluruh sehingga perlunya proses tambahan untuk mengupas kelapa 100\%, sehingga perlu adanya perbaikan terhadap mekanisme alat pengupas kelapa yang sudah ada sebelumnya. Penelitian yang dilakukan oleh Yunita Djamalu walaupun memiliki beberapa kekurangan yang dapat mengurangi fungsi dan tujuan dari alat tersebut, namun akan sangat membantu banyak petani kelapa untuk meningkatkan produktifitas dari petani kelapa. Penelitian ini berupaya merancnag alat sedemikian agar proses lebih cepat dan kelapa yang dihasilkan terkupas secara utuh. Hal ini dilakukan dengan menambahkan motor listrik. Penggunaan motor listrik dengan daya yang lebih besar dapat meningkatkan kecepatan dari alat tersebut untuk melakukan pengupasan sehingga petani dapat menghemat waktu dan tenaga. Pemilihan motor listrik yang sesuai juga akan membantu petani menghemat biaya dalam memproduksi kopra. Perbaikan dari alat pengupas kelapa tersebut perlu dilakukan mengingat alat yang dibuat sebelumn ya memiliki tujuan untuk membantu petani.

Penelitian ini bertujuan untuk merancang ulang Alat Pengupas Kelapa yang sebelumnya sudah pernah ada, dengan menganalisa kekurangan dari alat tersebut menggunakan Metode TRIZ (Teoriya Rashendiya Izobretatelskikh Zadath). Metode TRIZ sendiri adalah metode yang digunakan untuk melakukan analisa secara sistematis terhadap perbaikan dan perancangan ulang pada alat pengupas kelapa yang sudah ada sebelumnya. Metode TRIZ dipilih, antara lain karena juga dapat digunakan dalam mengevaluasi kinerja alat pengupas kelapa sebelumnya, dengan menghadirkan beberapa kontradiksi pada usulan perbaikan yang harus dihilangkan. Mekanisme tersebut sangat tepat untuk digunakan untuk menemukan kekurangan dari alat terdahulu, sebagai langkah pencarian solusi atau perbaikan alat ini.

\section{METODE}

Metode TRIZ sendiri adalah metode yang dirancang dan dibuat oleh seorang ahli berkebangsaan Rusia yang bernama Genrich Altshuller pada tahun 1946. TRIZ sendiri merupakan singkatan dari Teoriya Rashendiya Izobretatelskikh Zadath. Teoriya Rashendiya Izobretatelskikh Zadath berasal dari bahasa Rusia yang berarti Theory Of Inventive Problem Solving, dalam bahasa Inggris. Jika diterjemahkan ke dalam bahasa Indonesia berarti Teori Pemecahan Masalah Inventif.

Altshuller memulai penelititannya berdasarkan beberapa pattern. Hasil dari penelitiannya adalah sebuah matriks yang terdiri dari 39 parameter dan 40 prinsip. Tujuan utama penelitian tersebut adalah untuk mencari solusi atau panduan dalam proses inovasi ataupun pembuatan ide-ide baru. Hal ini dihasilkan melalui pengembangan inovasi yang selama ini digunakan, seperti metode trial and error, misalnya: brainstorming, syntetics dan morphological analysis.

Perancangan Mesin Pengupas dan Pembelah Kelapa dengan Menggunakan Metode TRIZ / Yohanes Patrik Adventus Banda, Julius Mulyono, Hadi Santosa

Peer reviewed under responsibili of Universitas Muhammadiyah Sidoarjo. 
TRIZ merupakan pendekatan sistematik untuk pemecahan berbagai permasalashan secara kreatif. TRIZ merupakan metode untuk membantu menyelesaikan masalah dengan dasar pengalaman terdahulu, yaitu menghilangkan permasalahan yang sifatnya kontradiksi. Dalam aplikasinya, terdapat beberapa tahapan dan langkah-langkah untuk dapat menggunakan metode TRIZ. Berikut adalah beberapa tahapan dalam penggunaan Metode TRIZ :

1. Mendeskripsikan masalah awal yang ingin diselesaikan.

2. Menyesuaikan dan melakukan perbandingan antara masalah umum dan TRIZ problems.

3. Mencari solusi menggunakan metode TRIZ.

4. Mengembangkan solusi ideal untuk pemecahan masalah.
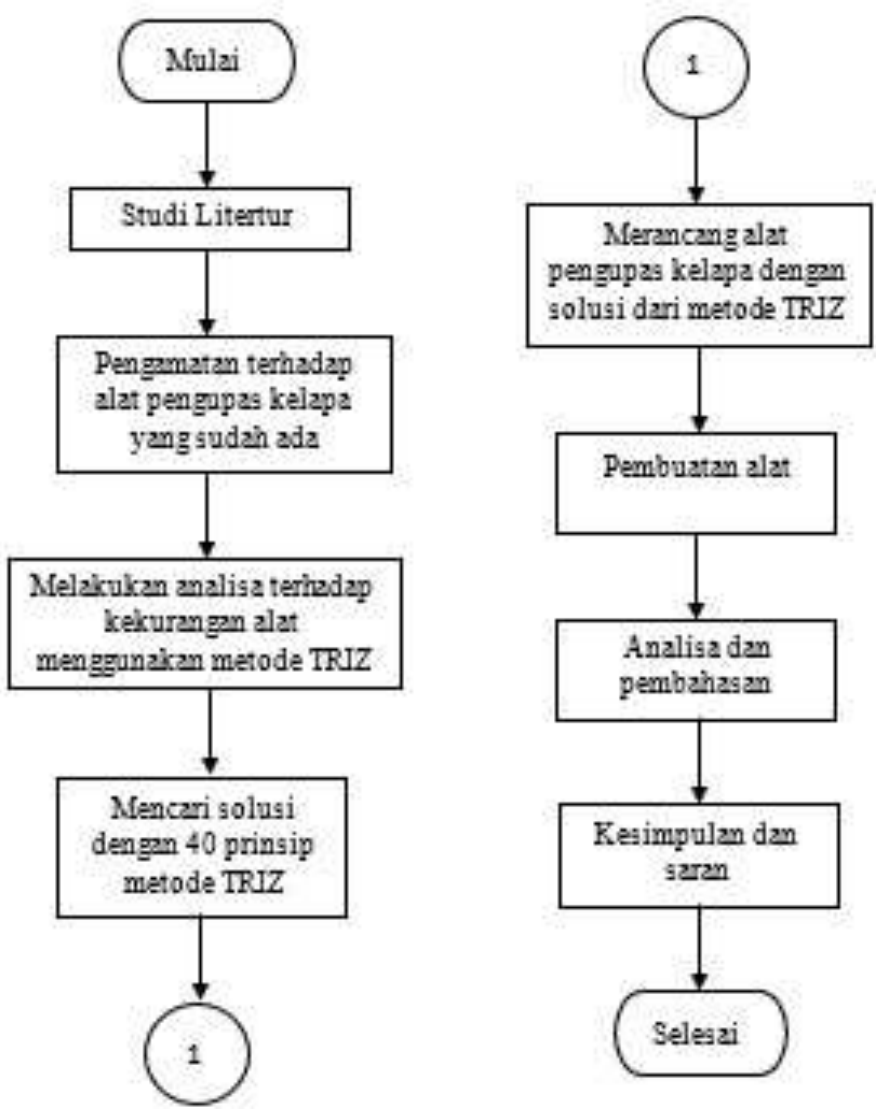

Gambar 1. Flowchart Metodologi Penelitian

\section{HASIL DAN DISKUSI}

Pada penelitian ini, perancangan diawali dengan menyusun daftar kebutuhan, dengan memperhatikan 40 prinsip yang ada pada metode TRIZ. Hal ini dilakukan dengan tujuan memperoleh inventive principle, seperti yang tercantum pada Tabel 1 berikut.

Perancangan Mesin Pengupas dan Pembelah Kelapa dengan Menggunakan Metode TRIZ / Yohanes Patrik Adventus Banda, Julius Mulyono, Hadi Santosa

Peer reviewed under responsibili of Universitas Muhammadiyah Sidoarjo.

(C) 2021 Universitas Muhammadiyah Sidoarjo. All Right reserved. This is an open access article under the CC BY licence (http://creativecommons.org/licences/by/4.0/ ) 


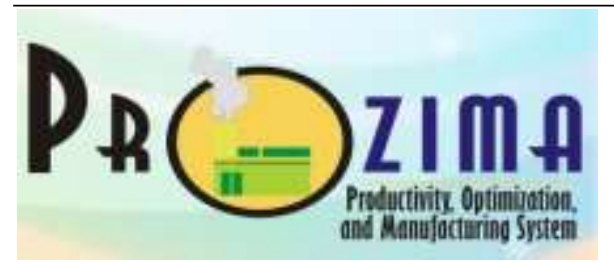

Prozima : Vol. 5, No. 2, Desember 2021, 86-92

E-ISSN. 2541-5115

Journal Homepage: http://ojs.umsida.ac.id/index.php/prozima

DOI Link: http://doi.org/10.21070/prozima.v5i2.1390

Article DOI: http://doi.org/10.21070/prozima.v5i2.1390

Tabel 1. Matriks Parameter Desain-Inventive Principle

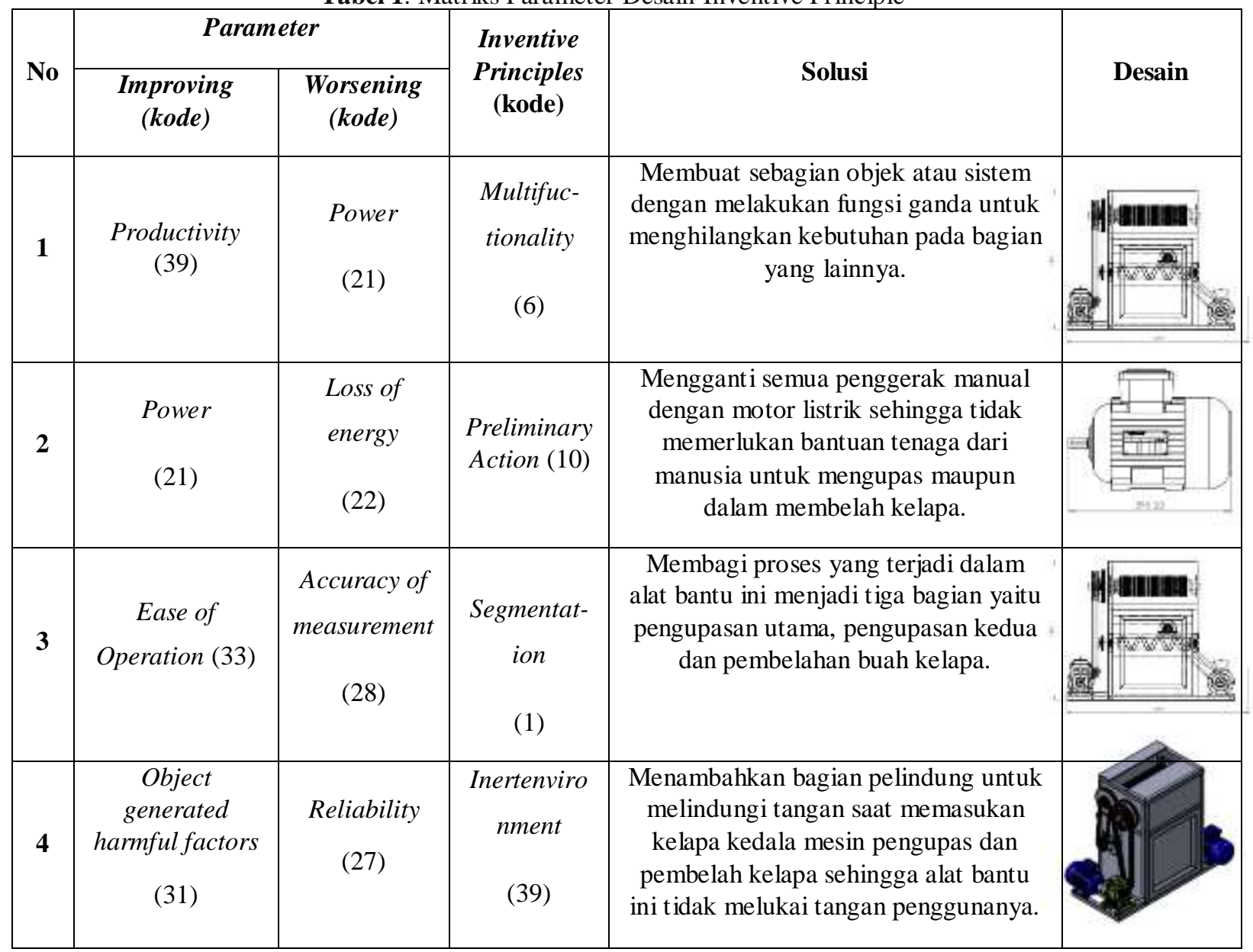

Keterangan untuk Tabel 1:

1. Peningkatan produktivitas dilakukan dengan prinsip penggandaan fungsi, yaitu penggunaan motor listrik daya besar, agar menghasilkan torsi yang kuat untuk gerakan-gerakan yang diperlukan.

2. Penggunaan motor listrik akan mengefektifkan proses yang sebelumnya dikerjakan secara manual. Hal ini untuk menghilangkan keburukan kinerja manual yang disebabkan faktor kelelahan.

3. Tujuan bagian ini adalah melakukan spesifikasi langkah atau proses, sehingga menjadi lebih detil, yang selanjutnya diharapkan menghasilkan gerakan-gerakan yang lebih akurat.

4. Keamanan merupakan hal penting yang perlu sangat diperhatikan. Dalam hal ini menyangkut keselamatan operator atau pekerja.

Berdasarkan hasil observasi dan pengamatan terhadap alat pembuka kelapa yang sudah ada sebelumnya maka didapatkan beberapa kriteria untuk mendesain atau merancang alat bantu pengupas dan pembelah kelapa. Kriteria dari alat pengupas dan pembelah kelapa adalah sebagai berikut:

Perancangan Mesin Pengupas dan Pembelah Kelapa dengan Menggunakan Metode TRIZ / Yohanes Patrik Adventus Banda, Julius Mulyono, Hadi Santosa

Peer reviewed under responsibili of Universitas Muhammadiyah Sidoarjo.

(C) 2021 Universitas Muhammadiyah Sidoarjo. All Right reserved. This is an open access article under the CC BY licence (http://creativecommons.org/licences/by/4.0/ ) 
a. Mampu mengupas dan membelah kelapa dengan lebih efisien (waktu lebih cepat)

b. Mudah untuk dioperasikan.

c. Aman (safe) saat digunakan.

d. Kuat dan tahan terhadap kondisi getaran yang ditimbulkan oleh motor penggerak

e. Kelapa dapat terkupas dengan sempurna.

Langkah berikutnya adalah pembuatan alat, dengan beberapa komponen sederhana dan proses permesinan. Beberapa penyesuaian dilakukan untuk memperoleh hasil yang terbaik. Gambar desain alat dan foto alat yang sudah direalisasikan ada pada Gambar 1. Sedangkan Tabel 2 memuat kebutuhan biaya dalam merealisasikan alat tersebut.
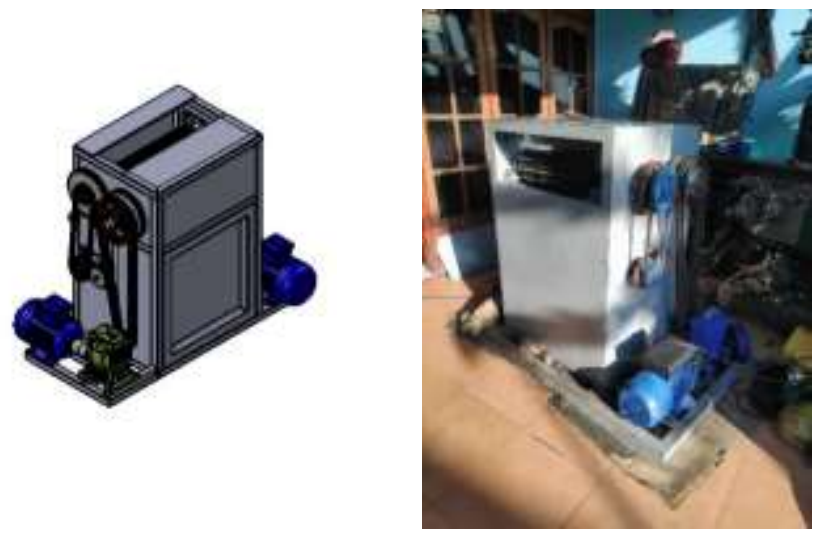

Gambar 2. Desain dan Photo Alat Pengupas dan Pembelah Kelapa

Tabel 2. Biaya Pembuatan Alat

\begin{tabular}{|c|l|c|lr|rr|}
\hline No. & \multicolumn{1}{|c|}{ Nama Komponen } & Jumlah & \multicolumn{2}{c|}{ Harga Satuan } & \multicolumn{2}{c|}{ Total Biaya } \\
\hline 1 & Rol pengupas I & 2 & Rp. & 1.000 .000 & Rp. & 2.000 .000 \\
\hline 2 & Siku & 1 & Rp. & 500.000 & Rp. & 500.000 \\
\hline 3 & Rol pengupas II & 2 & Rp. & 750.000 & Rp. & 1.500 .000 \\
\hline 4 & Motor listrik 3 PK & 1 & Rp. & 4.500 .000 & Rp. & 4.500 .000 \\
\hline 5 & Motor listrik 1/2 PK & 1 & Rp. & 750.000 & Rp. & 750.000 \\
\hline 6 & Cover pengupas & 4 & Rp. & 125.000 & Rp. & 500.000 \\
\hline 7 & Pembelah kelapa & 1 & Rp. & 150.000 & Rp. & 150.000 \\
\hline 8 & Ongkos bubut & - & - & & Rp. & 1.000 .000 \\
\hline 9 & Ongkos las & - & - & & Rp. & 2.000 .000 \\
\hline 10 & Lain-lain & - & - & & Rp. & 100.000 \\
\hline \multicolumn{2}{|c|}{ Total Biaya Pembuatan } & & & & Rp. & 13.000 .000 \\
\hline
\end{tabular}

Total biaya yang dihabiskan dalam perancangan dan pembuatan alat bantu pengupas dan pembelah kelapa adalah Rp 13.000.000.

Setelah dilakukan beberapa modifikasi dan perbaikan, maka dilakukan uji coba. Uji coba berupa proses pengupasan kulit kelapa dan pembelahan. Beberapa pengukuran dilakukan untuk melakukan perbandingan sederhana terhadap proses serupa yang menggunakan alat atau metode lama. Tabel 3 memuat perbandingan waktu proses antara penggunaan alat lama dengan alat baru.

Perancangan Mesin Pengupas dan Pembelah Kelapa dengan Menggunakan Metode TRIZ / Yohanes Patrik Adventus Banda, Julius Mulyono, Hadi Santosa

Peer reviewed under responsibili of Universitas Muhammadiyah Sidoarjo.

(C) 2021 Universitas Muhammadiyah Sidoarjo. All Right reserved. This is an open access article 
Journal Homepage: http://ojs.umsida.ac.id/index.php/prozima

DOI Link: http://doi.org/10.21070/prozima.v5i2.1390

Article DOI: http://doi.org/10.21070/prozima.v5i2.1390

Tabel 3. Perbandingan Waktu Proses Alat Lama dengan Alat Baru.

\begin{tabular}{|l|c|c|c|}
\hline \multirow{2}{*}{ No. } & Alat Lama (2 Proses Terpisah) (detik) & \multirow{2}{*}{ Alat Baru (detik) } \\
\cline { 2 - 3 } & Pengupasan & Pembelahan & 46,08 \\
\hline 1 & 34,96 & 20,05 & 45,23 \\
\hline 2 & 38,25 & 16,00 & 43,31 \\
\hline 3 & 27,30 & 19,25 & \\
\hline
\end{tabular}

Rata-rata dengan Alat Lama $=51,95$ detik / kelapa

Rata-rata dengan Alat Baru $=44,87$ detik $/$ kelapa

Pada alat baru yang dirancang terdapat penggunaan energi listrik. Berikut adalah data perhitungan ongkos penggunaan Alat Baru:

Daya listrik yang digunakan: 0,6371 Kwatt.

Konsumsi listrik dalam satu jam: 38,226 Kwh.

Jumlah kelapa dikerjakan dalam satu jam: 80 biji.

Tarif listrik = Rp. $1.115 / \mathrm{Kwh}$.

Total biaya $=\operatorname{Rp} 42.622$.

Biaya per kelapa $=$ Rp. 533 .

Pada Gambar 3 terlihat photo salah satu hasil dari proses di alat baru. Potongan kelapa terlihat sudah terkupas dan terbelah dengan baik.

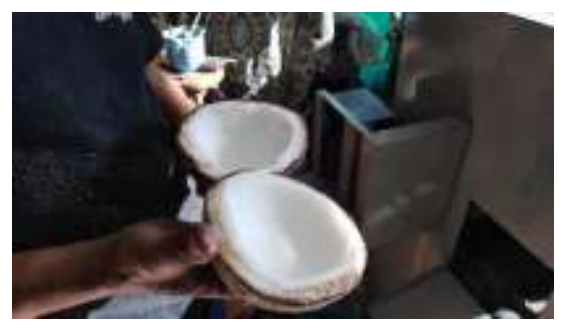

Gambar 3. Kelapa Hasil Pengupasan dan Pembelahan dengan Alat Baru

Waktu rata-rata yang didapat dari proses menggunakan alat yang baru adalah 44,87 detik per kelapa dengan tingkat penghematan waktu sebesar 7,05 detik per kelapa. Waktu tersebut adalah total waktu dalam melakukan proses pengupasan dan pembelahan kelapa. Waktu rata-rata yang dihabiskan dengan menggunakan alat lama ditambah waktu proses pembelahan yang dilakukan untuk membelah adalah sebesar 51,95 detik per kelapa. Hal ini menunjukkan bahwa alat yang baru lebih unggul dari segi durasi pengerjaan, yaitu lebih cepat sekitar 7 detik setiap biji kelapa.

\section{KESIMPULAN}

Hasil dari perancangan dan pengujian alat bantu pengupas dan pembelah kelapa adalah sebagai berikut:

1. Rata-rata waktu proses yang diperoleh dari percobaan adalah 44,87 detik per kelapa dengan penghematan waktu proses 7,08 detik per kelapa.

2. Biaya perancangan dan pembuatan alat pengupas dan pembelah kelapa ini adalah Rp 13.000.000.

3. Biaya produksi bertambah sebesar Rp. 533 per kelapa.

Perancangan Mesin Pengupas dan Pembelah Kelapa dengan Menggunakan Metode TRIZ / Yohanes Patrik Adventus Banda, Julius Mulyono, Hadi Santosa

Peer reviewed under responsibili of Universitas Muhammadiyah Sidoarjo.

(C) 2021 Universitas Muhammadiyah Sidoarjo. All Right reserved. This is an open access article under the CC BY licence (http://creativecommons.org/licences/by/4.0/ ) 


\section{DAFTAR PUSTAKA}

[1] Rantanen, K; Domb, E. 2002. Simplified TRIZ New Problem-Solving Applications for Engineers and Manufacturing Professionals. ST. Lucie Press: New York.

[2] Mulyono, Julius; Angka, Peter R., (2011), Aplikasi Teknologi dalam Kehidupan Sehari-Hari, Prosiding Seminar Nasional Teknik Industri dan Kongres Badan Kerja Sama Penyelenggara Pendidikan Tinggi Teknik Industri (BKSTI) VI ISBN 978-602-9997-0-5, Oktober 2011.

[3] Purnomo, Hari; Janari, Dian, (2015), Rancang Bangun Mesin Pengupas, Penghancur dan Pengayak Sabut Kelapa, Jurnal Spektrum Industri, Vol. 13, No. 1 ISSN : 2442-2630.

[4] Manongko, Jenly D. I; Rampo, Johanis (2016) Rancang Bangun Model Mesin Pengupas Kelapa Untuk Petani Kelapa Di Desa Wiau Kabupaten Minahasa Tenggara Propinsi Sulawesi Utara, Prosiding Semnastek 2016 ISSN 2407-1846.

[5] Abdullah, Haris; Botutihe, Sjahril; Djamalu, Yunita (2016), Pembuatan Alat Pengupas Sabut Kelapa Muda Sistem Putar, Jurnal Teknologi Pertanian Gorontalo (JTPG) e-ISSN 2503-2992 Volume 1, Nomor 2, Oktober 2016. 